Article

\title{
Evaluation of the Detachment Force Needed for Mechanical Thinning of Green Peach Fruits
}

\author{
Alberto Assirelli ${ }^{1}(\mathbb{D})$, Giuseppina Caracciolo ${ }^{2, *}(\mathbb{D})$, Mattia Cacchi ${ }^{2}$, Sandro Sirri ${ }^{2}$, \\ Federico Pallottino ${ }^{1}$ (i) and Corrado Costa ${ }^{1}$ (B) \\ 1 Consiglio per la Ricerca in Agricoltura e L'analisi Dell'economia Agraria (CREA) - Centro di Ricerca \\ Ingegneria e Trasformazioni Agroalimentari, via Della Pascolare 16, 00016 Monterotondo (RM), Italy; \\ alberto.assirelli@crea.gov.it (A.A.); federico.pallottino@crea.gov.it (F.P.); corrado.costa@crea.gov.it (C.C.) \\ 2 Consiglio per la Ricerca in Agricoltura e L'analisi Dell'economia Agraria (CREA)-Centro di Ricerca \\ Olivicoltura, Frutticoltura e Agrumicoltura, via la Canapona 1 bis, 47121 Forlì (FC), Italy; \\ mattia.cacchi@crea.gov.it (M.C.); sandro.sirri@crea.gov.it (S.S.) \\ * Correspondence: giuseppina.caracciolo@crea.gov.it; Tel.: +39-054-389-566
}

Received: 15 May 2018; Accepted: 29 June 2018; Published: 3 July 2018

check for updates

\begin{abstract}
As a result of mechanical fruit-thinning tests on various peach trees, difficulties in fruit detachment from branches were found for some cultivars. For this reason, and to create a database of the required detachment forces, the relationship between detachment and angle at which force is applied to the fruits was studied. The study was carried out in a peach orchard sited in Forlì, on four peach cultivars when the fruits were $20-40 \mathrm{~mm}$ in size. Using a dynamometer, the force required to detach fruits was measured, and different angles were evaluated to simulate the various ways in which the thinner hits fruits. The analysis of the different angles showed that, on average, fruits are detached more easily if the force is applied with a $90^{\circ}$ angle respective to the fruit position on the branch. On the other hand, if the force is applied with an angle of $0^{\circ}$, the average force required is three times higher. The study highlighted that adaptability to mechanical thinning is higher in some cultivars than in others. The results also showed that it is important to consider the impact angle of the thinner on fruits when evaluating the efficiency of the thinner machine.
\end{abstract}

Keywords: angle; crop load; cultivar; phenology; size; stone fruits; work windows

\section{Introduction}

Successful production of appropriate stone-fruit crops relies on achieving the desired crop load for each variety to produce a product of optimal size. Crop-load management is achieved by applying chemicals to make the fruit abort, or by removing flowers or fruitlets by hand or mechanical thinners. After many negative experiences with chemical thinning on different types of fruits [1,2], even in recent times [3], several thinning machines were developed for flowers [4] and fruits [5]. Mechanization of flower/green-fruit thinning increased, reducing thinning time and costs; however, results varied according to the species and device, as well as timing and orchard characteristics [6]. One of the challenges of modern fruit production is the use of advanced technologies to both identify and optimize the production process, and manage space-time variability in order to maximize economic returns, always in compliance with environmental constraints [7,8]. Machines developed for thinning use various techniques to remove the excess number of buds, flowers, or fruitlets: for example, shaking trees or branches [9], using spiked drums [10], or dragging and swinging strings through the tree canopies [11,12]. These all show great potential, as demonstrated by References [5,13], but a common disadvantage of the methods is their lack of efficiency: they are not-or are only partially-selective. The forces necessary for the detachment of the fruits were much studied, especially a few years ago, 
both for the development of robotic harvesting systems and for the development of automation and monitoring post-harvest, for example on strawberries [14], tomato [15], citrus [16], and pome fruit [17]. In reality, the thinning was not included in studies, especially in those on stone fruit. Detachment forces for fruit also have great importance for fruit harvesting. The authors of [18] showed that there was a direct relationship between fruit-detachment forces and mechanical-harvesting efficiency, thus highlighting the differences in propensity across varieties for mechanical harvesting, and the identification and setting of their main operational parameters. Research also works on the mechanical thinning of flowers and fruits, which are now achieved using machines that work by whipping the vegetation with rotary flails $[5,11,19,20]$, or by pushing and rubbing with free radial elements that rotate in contact with the plant [21].

Furthermore, it is difficult to optimize settings as there is no feedback with respect to the angle of tool application. Peach-thinning trials on fruits highlighted a special sensitivity to the action of the thinner machine, and the need for a deeper investigation into fruit resistance depending on the direction of tool application [21]. For Reference [22], the orientation of shoots in canopies of Y-trained peach trees significantly affected mechanical peach-thinning efficiency using a vibrating spiked-drum shaker [23]. Shoots that were vertically oriented, whether up or down, had fewer fruits removed than horizontal shoots, based on linear contrasts.

The distance and the inclination of the rotation axis of the rotor with respect to the row affect the level of penetration of tools into the vegetable canopy and, consequently, their thinning effect; thus, a deeper analysis is required. If we deviate from parallelism, the thinning effect is different in various parts of the canopy. In our trial, for which flower concentration (fertility index) of the upper canopy area was three times higher than that of the lower one, a greater inclination toward the row of the rotor's upper part would most likely allow the attenuation of the initial potential fertility imbalance of various parts of the canopy.

As a result of mechanical fruit-thinning tests on peach trees, there are difficulties in fruit detachment from the branches of some cultivars. Tests conducted on peach flowers showed that the efficiency of mechanical thinning [21] is closely linked to the time of intervention, with a very small work window outside of which the fruits are not detached. The presented study was carried out to test the forces required for fruit detachment in relation to the angle at which the force was applied to the fruits. This aspect could be the foundation for further study to identify the optimal work window for fruit mechanical thinning, especially for peach, as the work window of intervention with thinner machines is very narrow.

\section{Materials and Methods}

This study was conducted in May 2016 in Magliano, Forlì (Italy) at CREA-OFA (44ำ159962' N, $12^{\circ} 0804258^{\prime}$ E) using eight-year-old peach trees trained to a "vasetto" system, planted at $4 \mathrm{~m} \times 5 \mathrm{~m}$ (500 trees ha ${ }^{-1}$ ). In this system, each tree had four main scaffolds, two oriented on each side of the row and equally spaced from one another, in order to cover all the space around the tree. Three peach varieties and one peach selection were evaluated in these trials: Suncrest, Nectaross, Ghiaccio 1, and IFF 813 (Figure 1). Suncrest is a yellow-fleshed peach, Nectaross is a yellow-fleshed nectarine, Ghiaccio 1 is a deantocianic and stony-hard white-fleshed peach, and IFF 813 is a yellow-fleshed canning peach. Further information on the phenological stages of these cultivars is shown in Table 1. The fruit size was normalized by the "Norme di qualità delle pesche e nettarine (Prunus persica)" Reg. (CE) n. 2335/99 del 3/11/99 modifiche n. 46/03-n. 1861/04. 


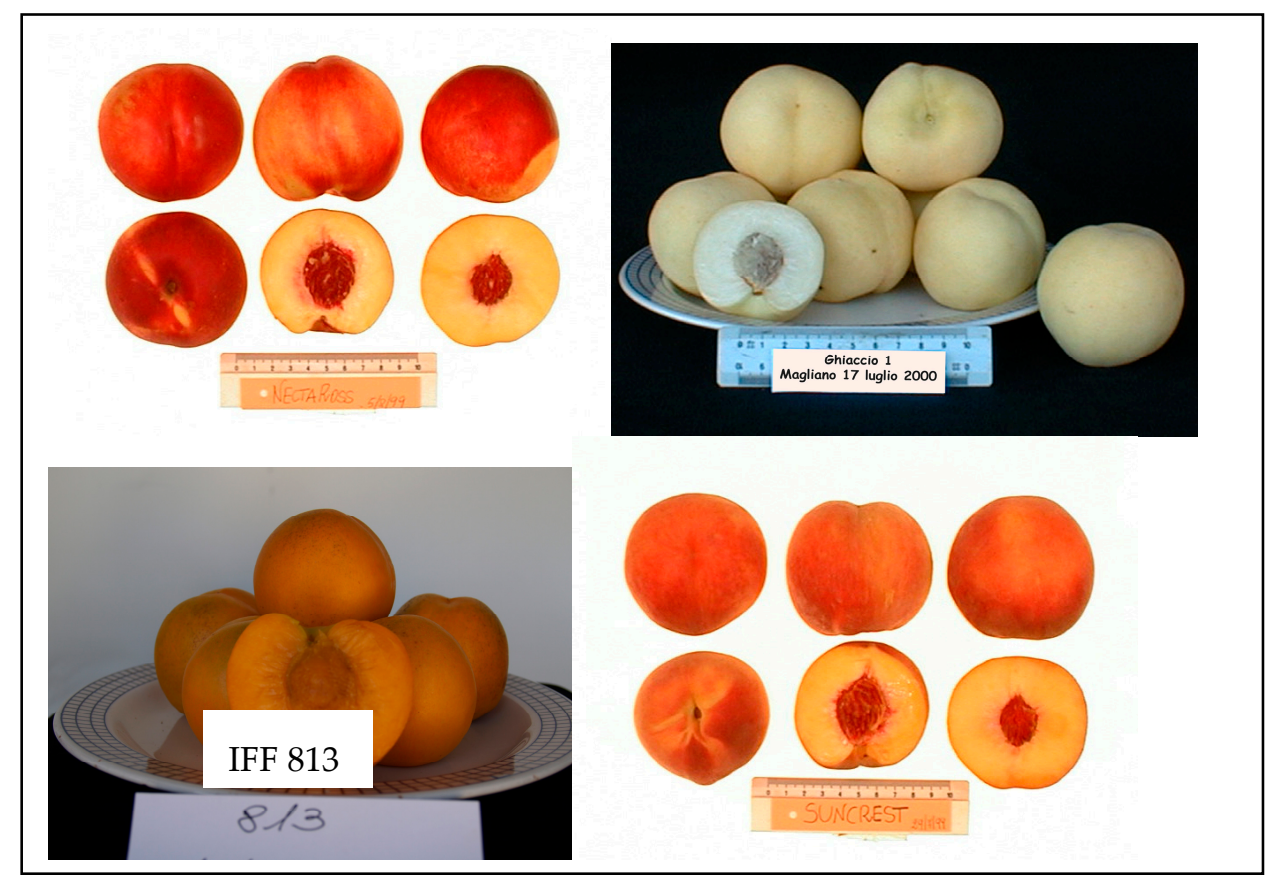

Figure 1. Fruits of the four tested varieties: Nectaross, Ghiaccio1, IFF 813, Suncrest.

Table 1. Phenological stages of the evaluated varieties, and time periods describing thinning with respect to full blooming and and harvest time.

\begin{tabular}{|c|c|c|c|c|c|c|c|}
\hline Varieties & $\begin{array}{c}\text { Fruit Size at } \\
\text { Harvest }\end{array}$ & $\begin{array}{l}\text { Blooming } \\
\text { Start (BB) }\end{array}$ & $\begin{array}{c}\text { Full } \\
\text { Blooming } \\
\text { (FB) }\end{array}$ & $\begin{array}{c}\text { End } \\
\text { Blooming }\end{array}$ & $\begin{array}{c}\text { Days after Full } \\
\text { Blooming } \\
\text { (DAFB) }\end{array}$ & $\begin{array}{c}\text { Harvest } \\
\text { Date }\end{array}$ & $\begin{array}{c}\text { Days before } \\
\text { Harvest }\end{array}$ \\
\hline IFF 813 & B & 13 March & 20 March & 26 March & 52 & 15 July & 65 \\
\hline Ghiaccio 1 & A & 19 March & 24 March & $28 \mathrm{March}$ & 48 & 12 July & 62 \\
\hline Suncrest & AA & 5 March & 10 March & 15 March & 62 & 23 July & 73 \\
\hline Nectaross & $\mathrm{A}$ & 1h March & 20 March & 25 March & 52 & 1 August & 82 \\
\hline
\end{tabular}

${ }^{*}$ AA: $73 \mathrm{~mm} \leq \varnothing<80 \mathrm{~mm} ; \mathrm{A}: 67 \mathrm{~mm} \leq \varnothing<73 \mathrm{~mm}$; B: $61 \mathrm{~mm} \leq \varnothing<67 \mathrm{~mm}$.

The test was performed on 11 May, when the fruit diameter was $20-40 \mathrm{~mm}$ for all varieties/selections. To measure the force necessary to detach green fruits from the branch, a dynamometer (FA10, SAUTER, Balingen, Germany) was used with a capacity of $5 \mathrm{~kg}$, and a graduation of $50 \mathrm{~g}$. A hook, specially built for this test, was fixed to it. The hook consisted of two thin spikes in the shape of an "L", placed $2 \mathrm{~cm}$ away from one another to keep the fruit near the peduncle. The dynamometer was applied to the fruit, and loaded with a force capable of detaching it from the branch. Four different force inclinations relative to the peduncle orientation were studied, to simulate different ways for the machine to interact with fruits during mechanical fruit thinning. In Figure 2, the four inclinations of application force are shown. The first was applied parallel to the peduncle orientation on the branch $\left(0^{\circ}\right.$ inclination), the second was applied with an inclination of $30^{\circ}$ with respect to the peduncle, the third was applied with an inclination of $60^{\circ}$, and the last was applied perpendicular to the peduncle $\left(90^{\circ}\right.$ inclination).

For each cultivar, the force required for the detachment of 60 fruits was measured, 15 for each studied angle. After the detachment of the fruit, it was collected and weighed by a digital scale with a sensitivity of $0.1 \mathrm{~g}$.

Finally, any correlations between fruit weight and detachment force were evaluated. Statistical data analysis was conducted using an artificial neural network (ANN). As the database was composed of a series of qualitative and quantitative variables, the best method of finding a regressive solution was a nonlinear approach, and for this reason, an ANN approach was applied. In a preliminary survey, 
linear regressive approaches (partial least squares) were tested, and returned low-performance models (data not shown).

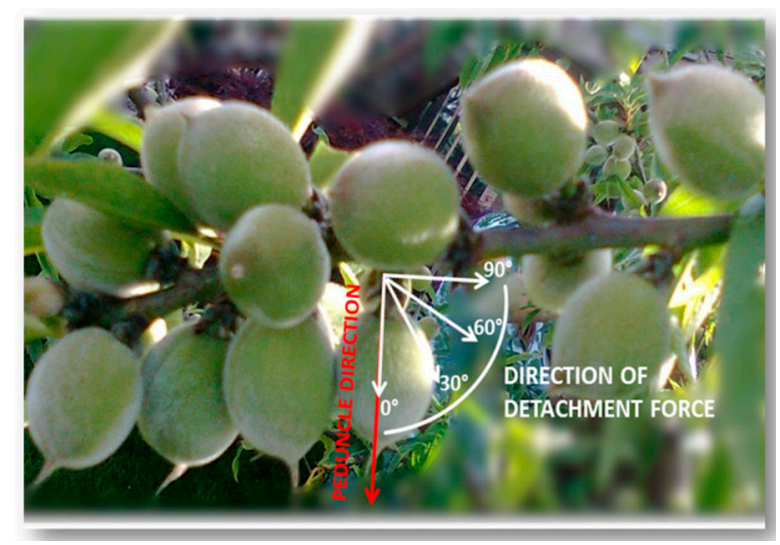

Figure 2. Direction of green-fruit detachment force.

An ANN was built based on the input and output layers. The input variables were included in the network's input layer. Moreover, the response variables with predictions, which represented the output of the nodes in this particular layer, were provided by the network. Additionally, a hidden layer was included. The type and complexity of the process or experimentation usually iteratively determine the optimal number of neurons in the hidden layers [24].

The input layer was composed of eight quantitative variables (angle of force application, fruit weight, full blooming (FB), end blooming, date of harvest, thinning days from FB, thinning days from harvest, and average fruit weight), and two qualitative variables (fruit size and variety). The ANN's purpose was to predict the force needed for fruit detachment (output layer). The ANN model was developed using a generalized regression neural network structure (GRNN), a method often used for function approximation [25]. The probability density function used in the GRNN was a normal distribution. GRNNs were trained with a back-propagation learning algorithm. To avoid overfitting [26], only 192 samples (80\%) were used to construct the ANN model (partitioning method). The remaining 48 samples (20\%) were then used to test the performance of the ANN model. The partitioning of the artificial datasets was optimally chosen with Euclidean distances, based on the algorithm described in Reference [27], which selects objects without a priori knowledge of a regression model (i.e., the hypothesis is that a flat distribution of the data is preferable for a regression model). The training of the ANNs was carried out using a learning factor equal to 0.5 and a momentum factor equal to 0.1. The training procedure was repeated 1,000,000 times, and the best performing ANN was selected based on the independent test set. Performance parameters, such as the $r$ correlation between observed and predicted values, and the root-mean-squared-error (RMSE) were reported for both training and test sets.

\section{Results and Discussion}

Fruit thinning was practiced for many years with several advantages. In fact, too many fruits per tree result in a small fruit size, poor quality, breakage of limbs, and the exhaustion of tree reserves (with consequent need to integrate nitrogen or other nutrients that can percolate into the ground), and can also inhibit bud initiation. Moreover, precision-farming technologies involving inherent harvesting and pre-harvest operations are currently more and more common, producing consistent environmental benefit and sustainability [28,29].

By improving the efficiency of mechanical fruit thinning, farmers can be encouraged to choose mechanical systems instead of chemical ones. Moreover, the results come faster, and when compared with manual thinning, should be preferred. This results in a significant reduction in emissions due 
to the consistently reduced time in the field of operators and machines. Indeed, workers operating manual thinning use tractors and trailers, where the engine always on. The implementation of mechanical thinning could substantially improve the economic and environmental sustainability along the production chain.

The average data related to the growth of detached green fruits showed that, at the time of the test, the cultivars used had scalar dimensions ranging from a minimum of $9.76 \mathrm{~g}$ for the Ghiaccio 1 cultivar up to $21.6 \mathrm{~g}$ of the Suncrest cultivar, with intermediate values for IFF 813 (13.3 g) and Nectaross (16.8 g).

However, the strength values applied for fruit detachment did not show any correlation with the recorded weight. Three of the considered cultivars (Ghiaccio 1, IFF 813, and Suncrest) had fruits with different weights at thinning time (ranging to $9.76 \mathrm{~g}$ and $21.6 \mathrm{~g}$ ), but similar detachment forces. Only Nectaross, with an intermediate fruit weight $(16.8 \mathrm{~g})$, exhibited a significantly higher release force (1025 g) when compared to other varieties (Figure 3).

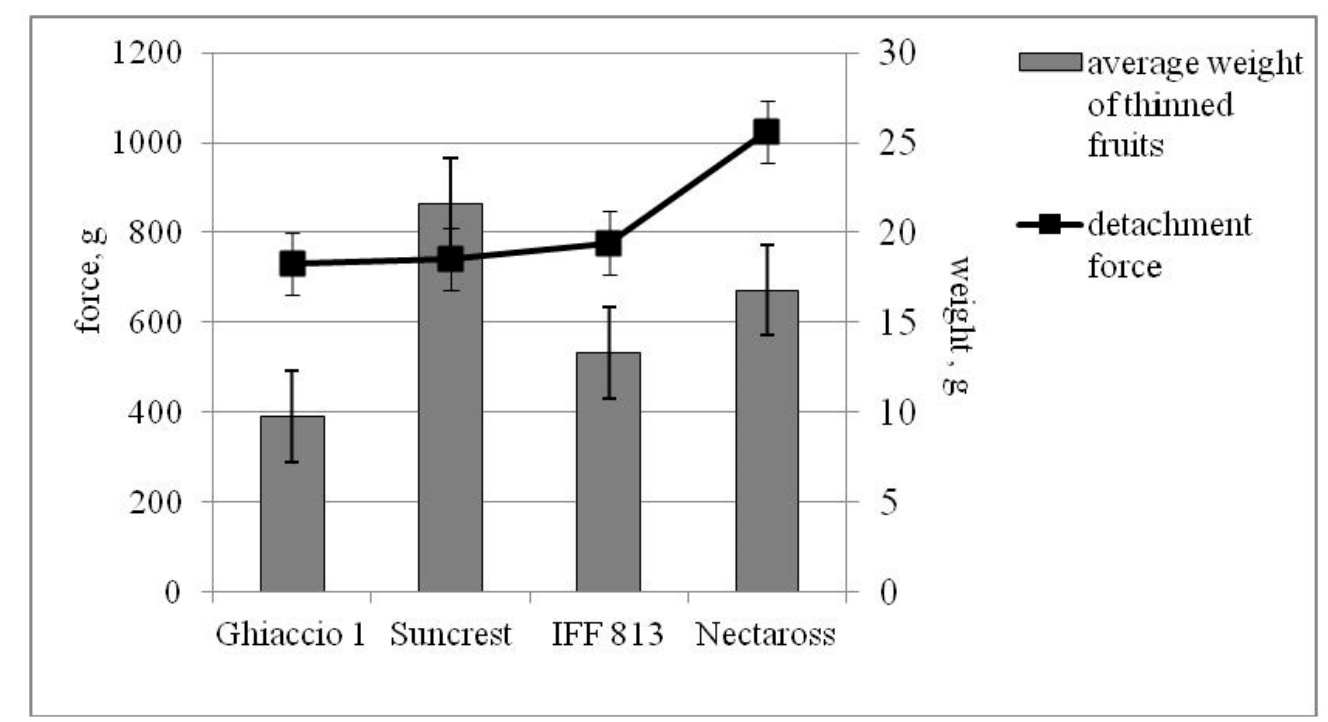

Figure 3. Detachment force and average fruit weight of the four varieties at thinning time (with bars of standard error).

By varying the application angle of the detachment force, the green fruits behaved as described in Figure 4.

Regardless of cultivar, the detachment angle was of great importance for the strength used in fruit thinning. At an inclination angle of $0^{\circ}$ (force parallel to the peduncle), fruits recorded medium detachment forces, higher than $1200 \mathrm{~g}$, which decreased into the 600-1000 $\mathrm{g}$ range for an inclination angle of $30^{\circ}$, into the $400-800 \mathrm{~g}$ range for the $60^{\circ}$ angle, and to lower than $500 \mathrm{~g}$ when detachment was perpendicular to the peduncle (angle of $90^{\circ}$ ). In each of the four considered directions, the Nectaross cultivar required the greatest detachment force (Figure 4). 


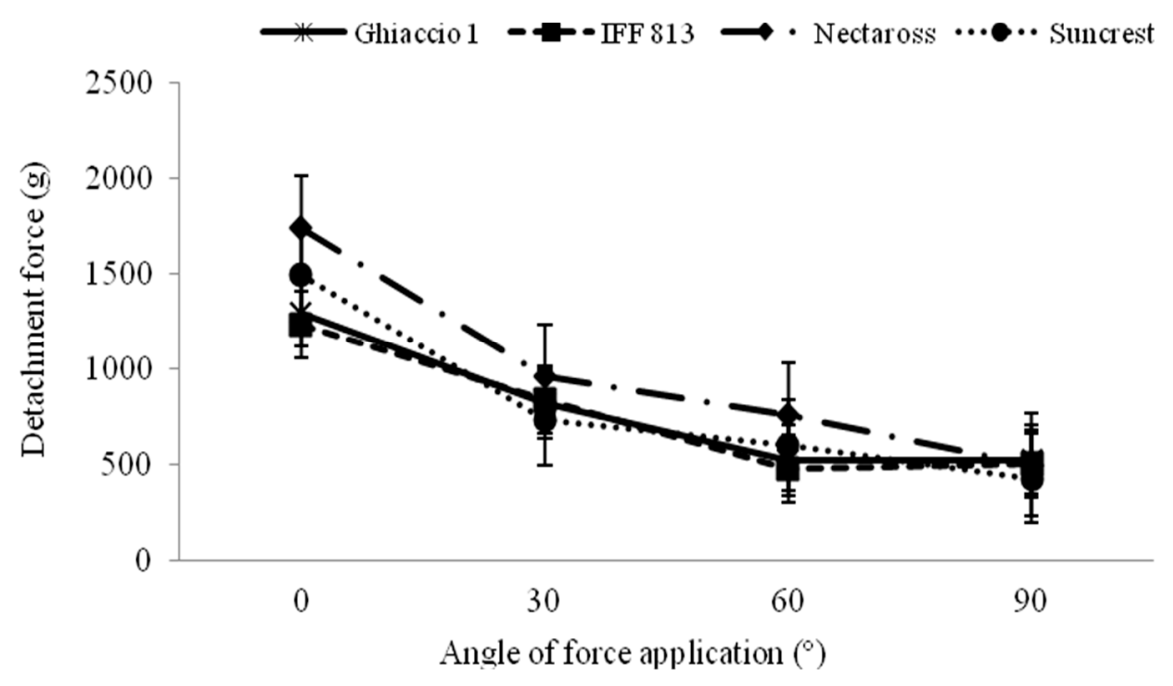

Figure 4. Cultivar comparison of detachment forces at different detachment angles (with bars of standard error).

The other phenological and pomological data were not shown to have any impact on the detachment force.

Table 2 shows the results of the performance of the GRNN model for the estimated forces needed for fruit detachment. The $r$ value for the external test ( $20 \%$ of the sample) seems to be quite good, and was equal to 0.77 . Meanwhile, the RMSE (test) results seem to be of an acceptable value, equal to 368.95, which was similar to the mean absolute error (MAE; test), equal to 269.38.

Table 2. Characteristics and principal results of the generalized regression neural network (GRNN) model in estimating the force needed for fruit detachment.

\begin{tabular}{cc}
\hline Number of Cases (training; 80\%) & 192 \\
Training Time & $00: 00: 01$ \\
Number of Trials & $1,000,000$ \\
$r$ Model & 0.7915 \\
Root-Mean-Squared Error (model) & 298.71 \\
Mean Absolute Error (model) & 231.26 \\
Standard Deviation of Absolute Error (model) & 189.07 \\
Number of Cases (test; 20\%) & 48 \\
$r$ (test) & 0.7756 \\
Root-Mean-Squared Error (test) & 368.95 \\
Mean Absolute Error (test) & 269.38 \\
Standard Deviation of Absolute Error (test) & 252.11 \\
\hline
\end{tabular}

The scatter plot in Figure 5 represents the observed versus predicted (using the GRNN model) force values, and shows a certain central tendency; however, on the right side of the figure, a group of diverging samples is clearly visible. 


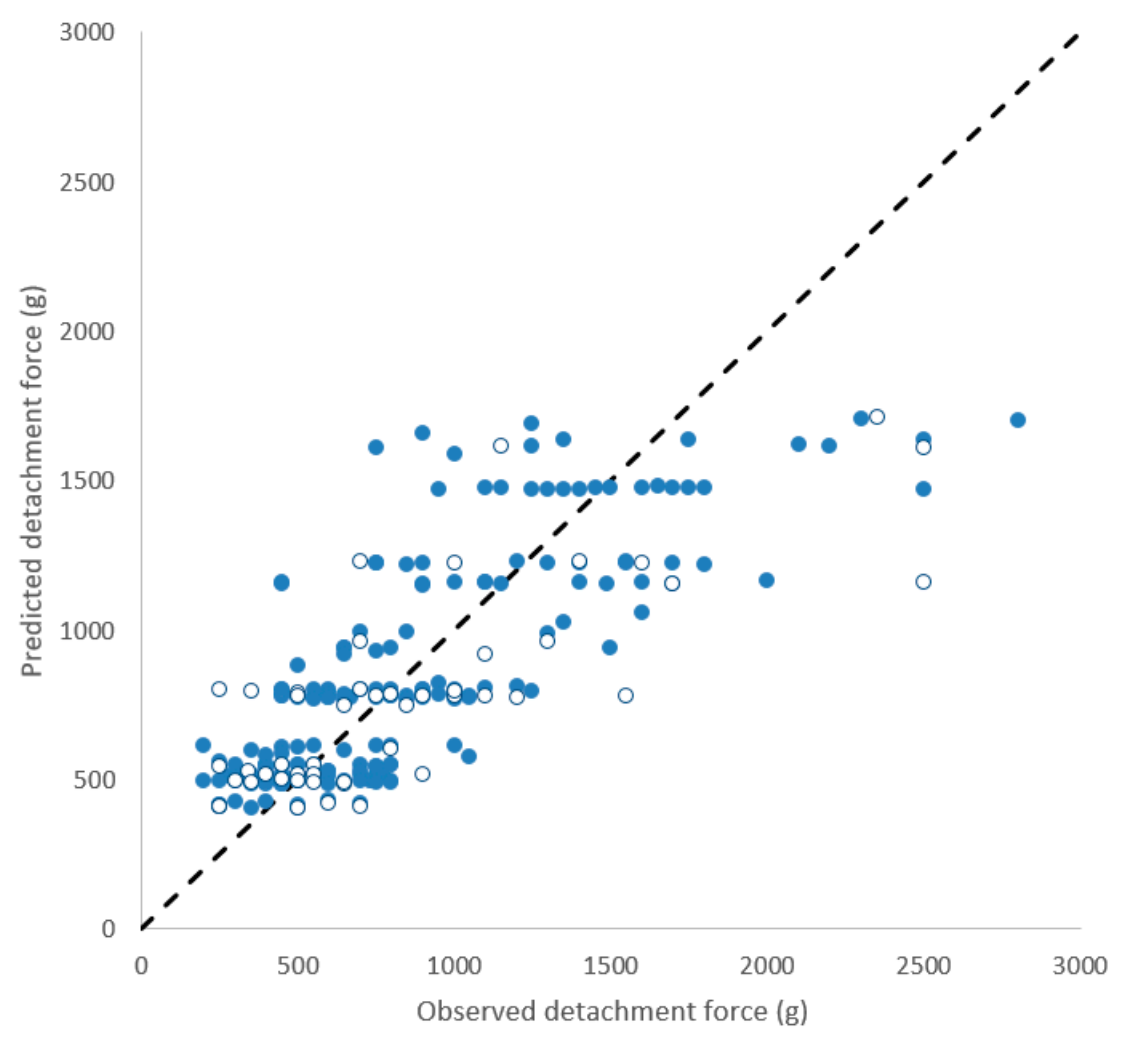

Figure 5. Scatter plot of the observed versus predicted (using the generalized regression neural network (GRNN) model) force needed for fruit detachment (g).

Regarding the weight of the variables included in the GRNN model (Figure 6), the impact of the angle of force application and fruit weight were important variables for more than $98 \%$ of the total analysis, while the others did not show any significance. This neat result confirms the cultivar comparison's (Figure 4) conclusion that the angle of force application is the most important variable for fruit detachment. Therefore, it must be taken into consideration for prototyping thinning machinery.

\section{Variable Impacts}

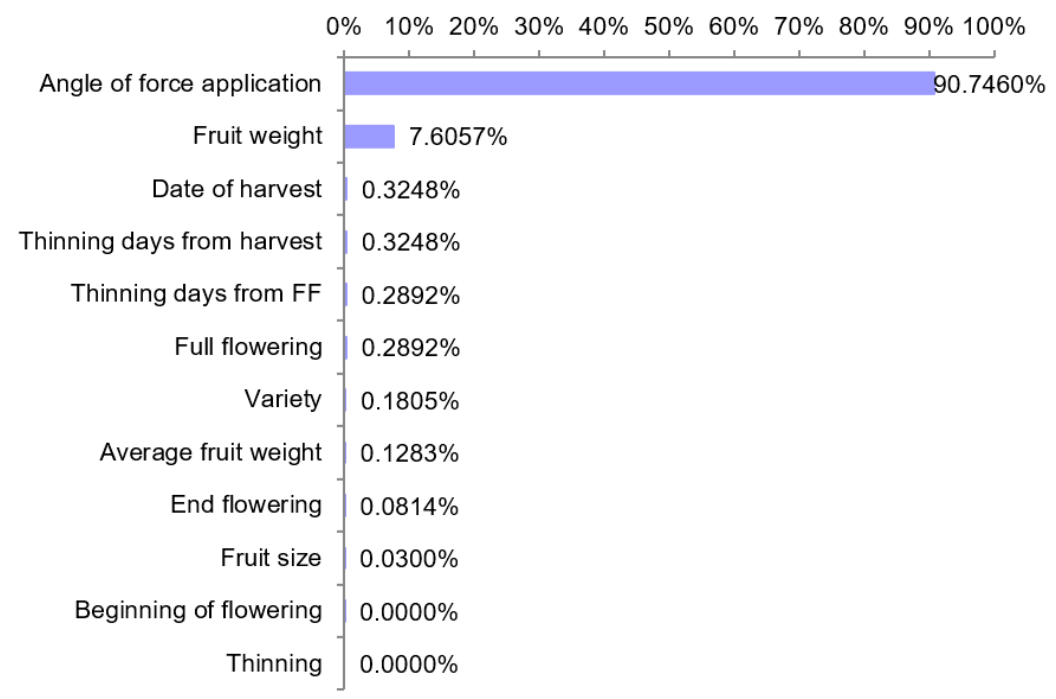

Figure 6. Variable impact analysis of the GRNN model. 
The angle of force application could affect the thinner's efficiency in relation to the functional type of thinning machine. Considering that thinning machines can be divided into two main types, driven by either a Power Take Off (PTO)/electric drum or a freewheel drum, the impact on the fruit can vary depending on the intensity of force transmitted. The two thinner typologies also allow different setting possibilities. The driven-drum machine can modify rotary and advanced speeds, as well as the energy impact needed for fruit detachment, regardless of the contact point. The freewheel-drum machine can only modify its ground speed, and the possibility of varying the detachment efficiency may be less than in the driven drum.

The elastic element that penetrates into the canopy shows different functional aspects. Unlike flexible elements, elastic elements can only beat, acting by thrusting or rubbing against fruits. As a result, the amount of energy needed to detach the fruit parallel to the peduncle or along the longitudinal axis of the fruit, which is also three times higher than the energy that is necessary in the radial plane, greatly reduces the efficiency of the machine's functional principle. It also opens greater possibilities for the elasticity of the peduncle itself to modify the application point, and possibly escape the push peak needed to determine the detachment of the peduncle from the shoot.

The peduncle resistance related to fruit variety is another important aspect, limiting the intervention period to only a few days. The fruit size at thinning time affects the possibility of being hit by the device elements, but effective detachment is determined via the peduncle resistance and, as a consequence, by the fruit variety and its corresponding phonological phase for thinning.

\section{Conclusions}

The study showed that the main factor affecting detachment strength is the angle of force application. The fruits that undergo forces perpendicular to the peduncle during mechanical thinning are more likely to be detached from the tree than others. This aspect should be considered in the evaluation of the efficiency of thinner machines; however, this is only one aspect of the complex processes that mechanical-thinning operations for thrust/rubbing or beating can encounter during work. All functional principles described are applied in both types of thinning machine. Driven and free systems can act with different levels of aggression; however, as highlighted in this experience, the values of longitudinal force necessary can make even the most energetic systems almost inefficient.

Taking into consideration the great variability in the fruit and stalk orientation on the branches, important differences were highlighted that could have a significant impact on the efficiency of the thinning machine, and its functional aspects. In the future, the relationship between fruit characteristics and optimal size at the time of detachment will be investigated by taking into account a larger number of cultivars, and by performing weekly subsequent thinning of the small fruit (20-40 $\mathrm{mm}$ in diameter) to evaluate its behavior over time, and to determine the optimal thinning time. The detachment forces detected were very different depending on the variety of fruit and the number of days from flowering. The latter aspect is very important for deciding the time of intervention with the machine, and according to its functional type (driven or free). From the first impressions, time of intervention should not be chosen according to the parameters traditionally followed with manual thinning

The different behavior of the Nectaross cultivar, the only nectarine in the analyzed pool, suggests that some cultivars have less adaptability than others to mechanical thinning. This feature seems to be due only to the structural characteristics of the fruits and not to their size at detachment time.

Preliminary knowledge of peduncle resistance to detachment in the orchard may allow the application of precision-agriculture concepts to modify the setting and aggression of the mechanical system according to training system, fruit variety, thinning time, etc., through a prevision or a simultaneous survey of flower/green-fruit load using optical systems. This is an important aspect in choosing the most suitable mechanical system for blooming or green-fruit thinning and application modes.

PTO/electric driven systems are only used for flowers, and seldom for green fruit, while freewheel systems are more widely used. With the aim of reducing management costs, a better integration 
between mechanical and hand thinning with precision-farming concepts, and the application of different forces to different parts of the tree canopy, characterized by more or less flower or fruit density, can be an important objective of research to evaluate the application of optical systems (Wouters et al., 2013).

Author Contributions: Conceptualization, A.A., G.C., M.C. and S.S.; Data curation, A.A., G.C., M.C., S.S., F.P. and C.C.; Formal analysis, F.P., G.C., A.A., and C.C.; Funding acquisition, A.A.; Investigation, A.A. and G.C.; Methodology, A.A., G.C., F.P. and C.C.; Project administration, A.A.; Resources, A.A.; Software, C.C. and F.P.; Supervision, G.C. and A.A.; Writing—original draft, A.A. and G.C.; Writing—review \& editing, A.A., G.C., F.P. and C.C.

Funding: This paper was funded with the contribution of the Italian Ministry of Agriculture, Food and Forestry Policies (MiPAAF) project AGROENER (D.D. n. 26329). All the authors equally contributed to the writing of the paper and to its content.

Conflicts of Interest: The authors declare no conflicts of interest.

\section{References}

1. Wertheim, S. Development in the chemical thinning of apple and pear. Plant Growth Regul. 2000, 31, 85-100. [CrossRef]

2. Continella, A.; La Rosa, G.; La Malfa, S. Peach Blossom Thinning with Ammonium Thiosulfate. ISHS Acta Hortic. 2015, 1084, 383-388. [CrossRef]

3. Khajehyar, R.; Rahemi, M.; Fallahi, E. The Impact of Various Rates and Dates of Gibberellic Acid Applications on Fruit Set in Apricot. Int. J. Fruit Sci. 2015, 5, 324-338. [CrossRef]

4. Asteggiano, L.; Giordani, A.; Bevilacqua, G.; Vittone, G.; Pellegrino, S.; Costa, G. Bloom mechanical thinning improve fruit quality and reduces production costs in peach. ISHS Acta Hortic. 2015, 1084, 389-394. [CrossRef]

5. Miller, S.; Schupp, J.; Baugher, T.; Wolford, S. Performance of mechanical thinners for bloom or green fruit thinning in peaches. HortScience 2011, 46, 43-51.

6. Webster, T. Current approved thinning strategies for apples and pears and recent thinning research trials in Europe. Compact Fruit Tree 2002, 35, 73-76.

7. Wouters, N.; De Ketelaere, B.; De Baerdemaeker, J.; Saeys, W. Hyperspectral waveband selection for automatic detection of floral pear buds. Precis. Agric. 2013, 14, 86-98. [CrossRef]

8. Emery, K.G.; Faubion, D.M.; Walsh, C.S.; Tao, Y. Development of 3-D range imaging system to scan peach branches for selective robotic blossom thinning. Am. Soc. Agric. Biol. Eng. 2010, 1009202. [CrossRef]

9. Rosa, U.; Cheetancheri, K.; Gliever, C.; Lee, S.; Thompson, J.; Slaughter, D. An electromechanical limb shaker for fruit thinning. Comput. Electron. Agric. 2008, 1, 213-221. [CrossRef]

10. Schupp, J.; Baugher, T.; Miller, S.; Harsh, R.; Lesser, K. Mechanical thinning of peach and apple trees reduces labor input and increases fruit size. HortTechnology 2008, 18, 660-670.

11. Baugher, T.A.; Schupp, J.; Ellis, K.; Remcheck, J.; Winzeler, E.; Duncan, R.; Johnson, S.; Lewis, K.; Reighard, G.; Henderson, G.; et al. String blossom thinner designed for variable tree forms increases crop load management efficiency in trials in four United States peach-growing regions. HortTechnology 2010, 20, 409-414.

12. Damerow, L.; Blanke, M. A novel device for precise and selective thinning in fruit crops to improve fruit quality. ISHS Acta Hortic. 2009, 824, 275-280. [CrossRef]

13. Solomakhin, A.; Blanke, M. Mechanical flower thinning improves the fruit quality of apples. J. Sci. Food Agric. 2010, 90, 735-741. [CrossRef] [PubMed]

14. Shigehiko, H.; Kenta, S.; Satoshi, Y.; Ken, K.; Yasushi, K.; Junzo, K.; Mitsutaka, K. Evaluation of a strawberry-harvesting robot in a field test. Biosyst. Eng. 2010, 105, 160-171.

15. Zhiguo, L.; Pingping, L.; Jizhan, L. Physical and mechanical properties of tomato fruits as related to robot's harvesting. J. Food Eng. 2011, 103, 170-178.

16. Chen, H.; McCollum, G.; Baldwin, E.; Bai, J. Impacts of Huanglongbing symptom severity on fruit detachment force and mechanical properties of sweet oranges (Citrus sinensis). HortScience 2016, 51, 356-361.

17. Caprara, C.; Ragni, L.; Torretta, F. Relation between Mechanical Damage and Morphology of the Impact Area in Apple Fruit. Available online: http:/ /agris.fao.org/agris-search/search.do?recordID=IT2000061194 (accessed on 5 June 2018). 
18. Torregrosa, A.; Ortì, E.; Martin, B.; Gil, J.; Ortiz, C. Mechanical harvesting of oranges and mandarins in Spain. Biosyst. Eng. 2009, 104, 18-24. [CrossRef]

19. Baugher, T.A.; Schupp, J.R.; Lesser, K.M.; Reichard, K.H. Horizontal String Blossom Thinner Reduces Labor Input and Increases Fruit Size in Peach Trees Trained to Open-center Systems. HortTechnology 2009, 19, 755-761.

20. Reighard, G.L.; Henderson, W.G. Mechanical blossom thinning in south Carolina peach orchards. ISHS Acta Hortic. 2012, 965, 117-122. [CrossRef]

21. Cacchi, M.; Sirri, S.; Caracciolo, G.; Giovannini, D.; Assirelli, A. Pesco: Diradamento Meccanico, L'effetto Sui Fiori; Speciale Pesco; Edizioni L'Informatore Agrario S.r.l.: Verona, Italy, 2016; Volume 27, pp. 36-39.

22. Glenn, D.M.; Peterson, D.L.; Giovannini, D. Mechanical thinning of peaches is effective Postbloom. HortScience 1994, 29, 850-853.

23. Peterson, D.L.; Kornecki, T. Shaking Mechanism for Fruit Harvesting. U.S. Patent 4,860,529, 29 August 1989.

24. Gupta, N. Artificial neural network. Netw. Complex Syst. 2013, 3, 24-28.

25. Specht, D.F. A general regression neural network. IEEE Trans. Neural Netw. 1991, 2, 568-576. [CrossRef] [PubMed]

26. Costa, C.; Menesatti, P.; Spinelli, R. Performance modelling in forest operations through partial least square regression. Silva Fenn. 2012, 46, 241-252. [CrossRef]

27. Kennard, R.W.; Stone, L.A. Computer aided design of experiments. Technometrics 1969, 11, $137-148$. [CrossRef]

28. Pallottino, F.; Biocca, M.; Nardi, P.; Figorilli, S.; Menesatti, P.; Costa, C. Science mapping approach to analyze the research evolution on precision agriculture: World, EU and Italian situation. Precis. Agric. 2018, 1-16. [CrossRef]

29. Pallottino, F.; Menesatti, P.; Figorilli, S.; Antonucci, F.; Tomasone, R.; Colantoni, A.; Costa, C. Machine vision retrofit system for mechanical weed control in precision agriculture applications. Sustainability 2018, 10, 2209. [CrossRef]

(C) 2018 by the authors. Licensee MDPI, Basel, Switzerland. This article is an open access article distributed under the terms and conditions of the Creative Commons Attribution (CC BY) license (http:/ / creativecommons.org/licenses/by/4.0/). 